\title{
Chemotherapy for Osteosarcoma without High-Dose Methotrexate: Another Piece in the Puzzle
}

\author{
Jean-Yves Blay \\ UJOMM Pavillon E, Hopital Edouard Herriot, and INSERMU590 Centre Leon Berard, Lyon, France
}

Osteosarcoma is a rare tumor which remains a major model in multidisciplinary oncology, bringing together pediatrician and adult oncologists, orthopedic surgeons, and pathologists, all requested for the optimal care of the patients [1].

Treatment with neoadjuvant [2] and/or adjuvant [3] chemotherapy is an undisputed standard for the management of these tumors, on the basis of randomized trials showing an improvement in relapse-free survival in patients treated with adjuvant or neoadjuvant chemotherapy vs. abstention [3, 4]. Neoadjuvant and adjuvant chemotherapy have yielded similar results in a small randomized trial comparing the 2 approaches [5]. Several cytotoxic agents have a demonstrated antitumor activity in osteosarcoma, namely high-dose methotrexate (HDMTX), doxorubicin, CDDP, and ifosfamide [1-7]; cyclophosphamide and vincristine were also frequently used but their antitumor activity is probably more limited, and these drugs are not included in modern chemotherapy regimens [1]. The above mentioned active cytotoxic agents have different toxicity profiles and constraints for administration and management. The administration of HDMTX requests a careful follow-up of patients for the monitoring of drug elimination, resulting in repeated 3-4 days hospitalizations of the patients, but its toxicity profile is otherwise favorable with limited alopecia and hematological toxicities. Conversely, doxorubicin, CDDP (cis-diaminedichloroplatinum; cisplatin), and ifosfamide treatments are associated with hematological toxicity, cardiac or renal side effects, and ototoxicity [1].

Determining the optimal combination of these agents for the management of patients with non-metastatic osteosarcoma has been the major question addressed by the clinical trials on osteosarcomas in the last 20 years [7-10]. Still, definitive answers are pending:

1) Should postoperative chemotherapy be adapted according to the quality of histological response to neoadjuvant chemotherapy on the primary tumor?
2) Should HDMTX be included in multi-agent protocols for osteosarcoma, or should more simple chemotherapy regimens be preferred?

The first question is currently being addressed by the EURAMOS trial, which randomizes different postoperative treatments according to the quality of the histological response achieved with a preoperative treatment combining HDMTX with CDDP and doxorubicin; in the postoperative phase ifosfamide is introduced for patients with poor histological response. The EURAMOS trial brings together cooperative groups from Europe and USA [11].

The second question has been explored by several randomized clinical trials, and uncontrolled clinical trials and is still a matter of discussion $[9,10]$. The first trial of the European Osteosarcoma Intergroup randomized HDMTX and doxorubicin with CDDP vs. the combination of doxorubicin and CDDP only [9]. The latter combination was found associated with improved disease-free survival, but concerns regarding the suboptimal dose intensity in the HDMTX arm led investigators to perform a second randomized trial, which compared the multidrug treatment derived from the T10 regimen [12] vs. a two-drug regimen with doxorubicin and CDDP (AP) in a larger $(n=407)$ cohort of patients [10]. In this latter trial, the AP combination yielded similar results in terms of survival, with a simplified treatment procedure for the patients and less protocol violations. Thus, combination chemotherapy regimens without HDMTX are considered by many investigators as efficient but simpler than HDMTX-based regimens while others still consider HDMTX as a necessary component of first-line treatment of osteosarcomas. To further investigate this question, additional series of patients with a long-term follow-up would be useful.

The report by P.R. Tunn and P. Reichardt in the current issue of ONKOLOGIE [13] adds novel information to this debate. These authors report here on a retrospective analysis of a non-

\begin{tabular}{ll}
\hline KARGER & ๑ 2007 S. Karger GmbH, Freiburg \\
Fax +497614520714 & Accessible online at: \\
$\begin{array}{l}\text { E-mail Information@Karger.de } \\
\text { www.karger.com }\end{array}$ & www.karger.com/onk \\
&
\end{tabular}

Prof. Dr. Jean-Yves Blay

UJOMM Pavillon E, Hopital Edouard Herriot

Place d'Arsonval, 69003 Lyon, and

INSERMU590 Centre Leon Berard

28, Rue Laennec, 69008 Lyon, France

E-mail blay@lyon.fnclcc.fr 
HDMTX-based regimen administered in 53 patients with osteosarcomas between 1983 and 1992. As expected a long follow-up is available for this series which include an exhaustive series of patients included in one institution. This is therefore a 'real life' situation, with a reasonable number of patients, in an admittedly retrospectively selected series from a single hospital. The authors have used a regimen which includes, in addition to CDDP at a $120 \mathrm{mg} / \mathrm{m}^{2}$ and doxorubicin at a $60 \mathrm{mg} / \mathrm{m}^{2}$ dose, cyclophosphamide and vincristine. Although the contribution of the 2 latter drugs is unclear, the combination of doxorubicin and CDDP, is given at a bit lower dose intensity than in the recent European Osteosarcoma Intergroup trials. In addition, no ifosfamide was given in these patients although this drug is a component of most recent chemotherapy regimens.

The outcome of these patients was found to be favorable: $45 \%$ of patients achieved a good histological response $(<10 \%$ residual cells), with 10-year event-free (EFS) and overall survival (OS) being 58 and $67 \%$ respectively. Although this series included no patients aged above 40 years, a subgroup with a worse prognosis [14], and only tumors of the extremities, these results are comparable to those achieved within clinical trials performed by the major cooperative groups in the field of osteosarcoma. For example a recent analysis of prognostic factors in 1,702 patients included in the studies of the COSS reported 58 and $61 \%$ EFS and OS, respectively, at 10 years [15]. The number of patients remains limited in this study though, precluding any well powered analysis of prognostic factors.

These survival results are consistent with recent publications of treatment series with non-HDMTX-based regimens, based on AP with $[7,8]$ or without $[9,10]$ ifosfamide. Interestingly, several of these non-HDMTX-based chemotherapy regimens were developed in adult patients while pediatricians tend to conserve the use of HDMTX in their current protocols [16-18].

This retrospective study confirms, in a series with a long-term follow-up, that treatment with chemotherapy regimens not including HDMTX can provide long-term survival at similar rates than the more complex regimens based on HDMTX. This study adds one piece to the puzzle which figures what is the optimal cytotoxic treatment for localized osteosarcoma. It is likely that this corpus of information will be used for defining the future protocols of adult patients. For children, however, most protocols still include HDMTX in 2007.

\section{References}

1 Link MP, Meyers PA, Gebhardt M: Osteosarcoma; in Pizzo PA, Poplack DG (eds): Principles and Practices of Pediatric Oncology, 4th ed. Philadelphia, Lippincott Williams and Wilkins, 2001, pp 1061-1069.

- Winkler K, Beron G, Kotz R, Salzer-Kuntschik M, Beck J, Beck W, Brandeis W, Ebell W, Erttmann R, Gobel U: Neoadjuvant chemotherapy for osteogenic sarcoma: results of a cooperative German/Austrian study. J Clin Oncol 1984;2:617-624.

3 Link MP, Goorin AM., Miser AW, et al: The effect of adjuvant chemotherapy, on relapse-free survival in patients with osteosarcoma of the extremity. N Engl J Med 1986;314:1600-1606.

4 Winkler K, Beron G, Delling G, Heise U, Kabisch H, Purfurst C, Berger J, Ritter J, Jurgens H, Gerein $\mathrm{V}$ : Neoadjuvant chemotherapy of osteosarcoma: results of a randomised cooperative trial (COSS 82) with salvage chemotherapy based on histological tumor response. J Clin Oncol 1988;6:329-337.

$\checkmark 5$ Goorin AM, Schwartzentruber DJ, Devidas M, Gebhardt MC, Ayala AG, Harris MB, Helman LJ, Grier HE, Link MP; Pediatric Oncology Group: Presurgical chemotherapy compared with immediate surgery and adjuvant chemotherapy for nonmetastatic osteosarcoma: Pediatric Oncology Group Study POG-8651. J Clin Oncol 2003;21(8): 1574-80.

6 Miser JS, Kinsella TJ, Triche TJ, Tsokos M, Forquer R, Wesley R, Horvath K, Belasco J, Longo DL, Steis R: Ifosfamide with mesna uroprotection and etoposide: an effective regimen in the treatment of recurrent sarcomas and other tumors of children and yound adults. J Clin Oncol 1987;5:1191-98.
7 Ferrari S, Smeland S, Mercuri M, Bertoni F, Longhi A, Ruggieri P, Alvegard TA, Picci P, Capanna R, Bernini G, Muller C, Tienghi A, Wiebe T, Comandone A, Bohling T, Del Prever AB, Brosjo O, Bacci G, Saeter G; Italian and Scandinavian Sarcoma Groups: Neoadjuvant chemotherapy with highdose ifosfamide, high-dose methotrexate, cisplatin, and doxorubicin for patients with localized osteosarcoma of the extremity: a joint study by the Italian and Scandinavian Sarcoma Groups. J Clin Oncol 2005;23:8845-52.

8 Meyers PA, Schwartz CL, Krailo M, Kleinerman ES, Betcher D, Bernstein ML, Conrad E, Ferguson W, Gebhardt M, Goorin AM, Harris MB, Healey J, Huvos A, Link, M, Montebello J, Nadel H, Nieder M, Sato J, Siegal G, Weiner M, Wells R, Wold L, Womer R, Grier H: Osteosarcoma: a randomized, prospective trial of the addition of ifosfamide and/or muramyl tripeptide to cisplatin, doxorubicin, and high-dose methotrexate. J Clin Oncol 2005;23:2004-11.

9 Bramwell VH, Burgers M, Sneath R, Souhami R, van Oosterom AT, Voute PA, Rouesse J, Spooner D, Craft AW, Somers R: A comparison of two short intensive adjuvant chemotherapy regimens in operable osteosarcoma of limbs in children and young adults: the first study of the European Osteosarcoma Intergroup. J Clin Oncol 1992;10:1579-1591.

10 Souhami RL, Craft AW, Van der Eijken JW, Nooij M, Spooner D, Bramwell VH, Wierzbicki R, Malcolm AJ, Kirkpatrick A, Uscinska BM, Van Glabbeke M, Machin D: Ransomised trial of two regimens of chemotherapy in operable osteosarcoma: a study of the European Osteosarcoma Intergroup. Lancet 1997;305:911-17.

11 EURAMOS, the European and American Osteosarcoma Study Group: www.ctu.mrc.ac.uk/euramos/.
12 Saeter G, Alvegärd TA, Elomaa I, Stenwig AE, Holmström T, Solheim OP: Treatment of osteosarcoma of the extremities with the T10 protocol with emphasis on the effects of preoperative chemotherapy with single-agent high-dose methotrexate : a Scandinavian Sarcoma Group Study. J Clin Oncol 1991;9:1766-1775.

13 PU Tunn, Reichardt P: Chemotherapy for osteosarcoma without high dose methotrexate: A 12 year follow-up. Onkologie 2007;30(5):228-232.

14 Grimer RJ, Cannon SR, Taminiau AM, Bielack S, Kempf-Bielack B, Windhager R, Dominkus M, Saeter G, Bauer H, Meller I, Szendroi M, Folleras G, San-Julian M, van der Eijken J: Osteosarcoma over the age of forty. Eur J Cancer 2003;39:157-63.

15 Bielack SS, Kempf-Bielack B, Delling G, Exner GU, Flege S, Helmke K, Kotz R, Salzer-Kuntschik M, Werner M, Winkelmann W, Zoubek A, Jurgens $\mathrm{H}$, Winkler K: Prognostic factors in high-grade osteosarcomas of the extremities or trunk: an analysis of 1,702 patients treated on neoadjuvant Cooperative Osteosarcoma Study Group protocols. J Clin Oncol 2002;20:776-790.

16 Patel SJ, Lynch JW Jr, Johnson T, Carroll RR, Schumacher C, Spanier S, Scarborough M: Doseintense ifosfamide/doxorubicin/cisplatin based chemotherapy for osteosarcoma in adults. Am J Clin Oncol 2002;25:489-95.

17 Biron P, Rolland F, Thyss A, et al: OSAD93: a multicentric prospective phase II study of preoperative high-dose ifosfamide and CDDP in adult patients with non-metastatic osteosarcoma (abstract 9019). Proc Am Soc Clin Oncol 2004;22:14S.

18 Piperno-Neumann S, Bui BN, Blay JY, et al: A multicentric prospective study of intensive induction chemotherapy (API-AI) in localized osteosarcoma patients: results of a phase II trial coordinated by the French Sarcoma Group (FSG) and the FN CLCC BECT. J Clin Oncol 2006;24(suppl 18S):9521. 